\title{
The Evaluation Model of College Students' Organizational Performance Based on Data Envelopment Analysis
}

\author{
Jiexiao Zhu \\ \{zhujiexiaosh@126.com\}
}

Department of Educational Administration East China Normal University, Shanghai 200062, China

\begin{abstract}
In this paper, we first introduce the performance evaluation of University and the historical background of the emergence and the development of the status quo, points out the problems and deficiencies of the present stage of our country higher education evaluation method exists, discusses the performance evaluation of colleges and universities in our country application practical significance; secondly, the related concepts and theoretical explanation of the performance evaluation of University, analyzes and introduces the methods of performance evaluation of University and data network analysis method of CCR and BCC model and of several different methods of comparison of advantages and disadvantages. Thirdly, this paper explains in detail the data envelopment analysis method has the advantages that are using this method. Since the end of ninety's last century, the development of higher education in China has made brilliant achievements, and the proportion of higher education has been ranked among the top of the world. How to make better use of education funding increased year by year, more effective configuration of the soft and hardware resources for education is a problem faced by our government, which directly affect the our country education country to a powerful nation in education to promote the pace. In this paper, based on the principle of the construction of the index, this paper improves the current educational performance evaluation index system, and forms a more reasonable evaluation index system. Finally, using the evaluation index system proposed in this paper, we have made an empirical study on the evaluation objects of 985 colleges and universities in China in 34 .
\end{abstract}

Keywords: Performance evaluation; higher education; CCR model; BBC model; data envelopment analysis

\section{Introduction}

Since 1950s, some western economists gradually found that the increase of human capital is one of the sources of economic growth, they try to spill economic action and other aspects of education from the definition of human capital, education cost and income, education funding, human resource prediction, education abroad, emphasizing the efficiency and effectiveness of education; at the same time, along with the vigorous development of management research, western countries try theory, method and model management is applied to evaluate the performance of the administrative work of government departments, some 
achievements have been made in the performance appraisal standards, methods and applications, including the extensive research on education evaluation. The first appeared in the United States. The first research on the input and output of education is to explain how the input of educational resources can be transformed into the output of education through the production function of computing education. In the sixties of the 20th century, American Schultz, British Wiese [1], U. S. Becker, western economists on education investment as is a kind of economic activity, and focus on the contribution of human capital to the economic growth and laid the foundation for the development of modern western economics of education. They believe that human capital is a form of capital and physical capital relative to exist. It shows in the human body, can be used to provide future income; and education is the most important way to the formation of human capital, education through the formation of human capital and the economic increase due to the effects of a continuous. By the mid seventies of last century, as a result of the decline of western economy and the development of higher education in the western developed countries facing serious challenge, the huge expenditure on education makes many countries had to go through increases in tuition and encourage cooperation between school and enterprise, to attract private investment in education and other methods to enhance the running efficiency and the benefit, in the rapid development of this period is the performance evaluation of university research stage. With the research on theory and methods of evaluation system of Germany gradually mature, performance evaluation for higher education has become an effective tool for western countries to evaluate the teaching situation, countries to develop education development strategy, allocation of educational funds and strengthening the comprehensive school management an important means, plays a more and more important role in the high school of management and development.

\section{The Related Concepts and Methods of Performance Evaluation in Colleges and Universities}

Performance evaluation (PerformanceAppraisal), also known as performance evaluation or performance evaluation, is a formal employee evaluation system, but also an important part of human resource management. Performance evaluation uses scientific evaluation theory and method to evaluate and measure the behavior ability and effect of employees on the job. Performance evaluation is the interaction between managers and employees in the management of a communication activities. Generally speaking, the results of performance evaluation can directly affect employee job, salary, bonus, etc. many vital interests, evaluation feedback but also to provide the basis for improving management system and method of management. Analytic hierarchy process (Analytic Hierarchy Process The, referred to as AHP), is a process of dealing with the economic, management and other complex factors, including the technical method [2]. Analytic hierarchy process method is to start with the complex problem is decomposed into multiple elements, and these elements according to dominance relation further decomposition, according to the target layer, criterion layer and index layer arranged from top to bottom, the formation of a multi-objective and multi hierarchy tree model; then by pairwise comparison determine each level in the composition factors of relative importance. 


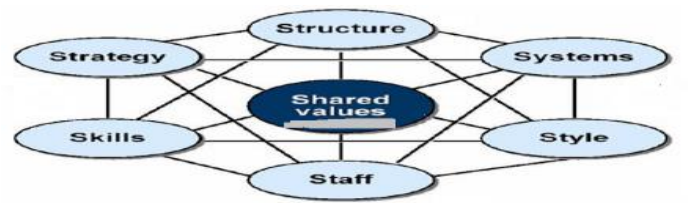

Fig. 1. Schematic diagram of performance evaluation model

\subsection{Fuzzy Hierarchy Comprehensive Evaluation Method}

Fuzzy comprehensive evaluation is a performance evaluation method based on fuzzy set theory, which can solve the incomplete information. Usually in the evaluation, due to the subjectivity of human thinking, evaluation index and qualitative measurements tend to more fuzzy with, the fuzzy hierarchy comprehensive evaluation method through the establishment of evaluation factors, weight of evaluation, fuzzy relationship and the judgment standard, and the fuzzy relationship synthetic operation, the ultimate goal is fuzzy evaluation object is relatively clear, the evaluation target to make reasonable and comprehensive evaluation [3].

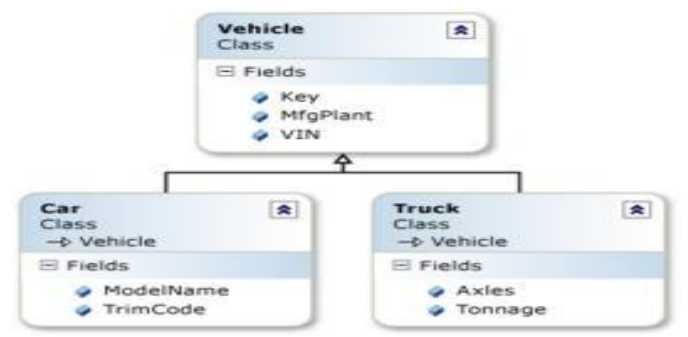

Fig. 2. Schematic diagram of fuzzy hierarchy comprehensive evaluation method

\subsection{Balance-counting-card Method}

Balance score card method (BSC), breaking the traditional focus only on financial indicators of performance management methods, it thinks, the organization from four dimensions to construct an index framework, these four dimensions are financial, financial, customer, internal business processes (internal business processes, learning and growth (learning and growth). Balanced score card to organizational strategy and mission into clear evaluation target and evaluation index, through the evaluation index measure with the purpose of evaluating the implementation, followed by the financial objectives of the organization reflect organizational planning and strategy implementation is in for the final operating profit to enhance play a role.

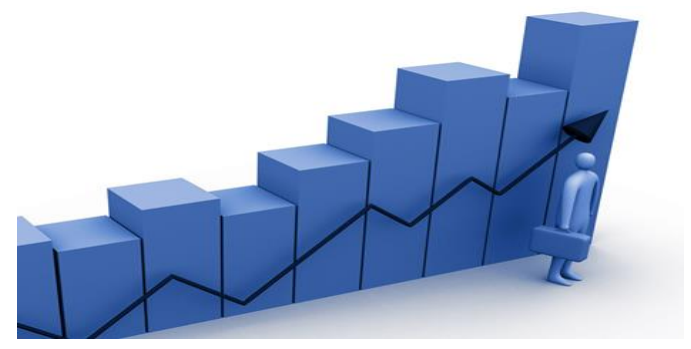


Fig. 3. Schematic diagram of the balanced scorecard

\subsection{Construction Principle of Index System}

Performance evaluation system of university is a complex and comprehensive system, which includes all aspects of economy, resources, social and human resources, these contents constitute the all dimensions of a university is involved in the development process, how to measure the comprehensive system, became the problem. In order to solve this problem, many domestic and international researches are used to construct the evaluation index system to reflect the performance of universities. Performance assessment system of colleges and universities from the essence, is a measure of an evaluation unit development ability, it is a series of multi-level and multi angle, mutually independent but complementary indicators of organic compound, index selection must follow certain principles and basis. Evaluation index system must be able to fully reflect the various aspects of the evaluation of colleges and universities, and to make the evaluation objectives and evaluation indicators linked together, form a distinct overall. The establishment of the index system should conform to the objective facts of the daily operation and management of the University, and can fully reflect the evaluation objectives. The index selection should be in accordance with the statistical standards, the stability of the data sources, the quantity of the index system is suitable. From the point of view of economic institutions of higher learning evaluation is in the operation of the market environment by of capital income and expenditure analysis and evaluation in Colleges and universities as a third party industry operation, overcomes wasteful and uneven distribution, clear in fund investment is how to translate into educational output. This kind of educational output not only refers to the financial profit, but also includes the scientific research achievement [4], the quantity and quality of the paper, the human capital, the economic and social development, such as the source of power and other intangible social resources.

\section{System Design and Modeling}

Investment in Colleges and universities, including tangible financial and material resources and intangible human input, and the financial investment, including the funding of science and technology, the cost of education, infrastructure construction and other inputs, these funds are mainly from the financial allocation, school income, student tuition and enterprise and social support; material inputs reflect is the hardware inputs, the required materials such as classrooms, dormitories, a library, a gymnasium, laboratory equipment and teaching activities; human input mainly reflect the input of teachers in Colleges and universities, but in addition to teachers and students, human investment also includes logistics personnel, management personnel and other aspects. China's institutions of higher learning with research on the performance evaluation in the nearly twenty years rapid development, many scientific research institutions and scholars have put forward different evaluation model and use a variety of evaluation methods, evaluation of the performance of the colleges and universities of our country is studied from the multi angle, but many of the current evaluation focus on economic indicators, while ignoring the principle of comprehensive performance evaluation of University, input of manpower, material resources and can not be comprehensive selection index. Therefore, colleges and universities, both from the economic 
point of view, but also from the point of view of hardware and teachers, this is the basis for the selection of input indicators. Performance is a broad concept that includes not only the economic performance, including technical performance, performance management, direct benefit, indirect benefit, and social benefits, so in the selected output indicators of education need to be clear, educational output refers not only to financial profit, more including scientific research, quantity and quality of papers, human capital, on the economic and social development source power and other intangible social resources. In many of the performance evaluation of university research, analytic hierarchy process method, 360 degree performance evaluation method, the fuzzy hierarchy comprehensive evaluation method, the Balanced Scorecard and DuPont analysis method has been widely used, but these methods there are different problems, and some need to assume the function relationship between the dependent and independent variables, and some need to get expert scoring through the questionnaire survey, evaluation index to determine the weights, this approach will inevitably result in the influence of subjective factors in the evaluation results [5].

\section{Conclusion}

The performance evaluation in the management of colleges and universities and its importance is self-evident, this paper choose data envelopment analysis method of 34 "985" universities and colleges of performance evaluation, can promote the optimal allocation of educational resources, better use of education funding increased year by year, more effective configuration of software and hardware of educational resources, as well as the management of colleges and universities and disciplines construction work put forward the suggestions for the improvement of the, the exploration and study of higher education in our country how to from the development of education country into a powerful nation of education is the key. By using the data envelopment analysis (DEA) method of CCR model, in 34 universities of overall efficiency evaluation, found to have 9 universities achieve DEA effective, the other 25 colleges and universities belong to the non DEA effective, which $94.12 \%$ of the efficiency of the numerical distribution within the scope of the 0.5 , indicating that the overall effectiveness of the "985" of universities and colleges in our country is still relatively high. But the non DEA effective universities are mainly affected by the pure technical efficiency, so these universities should strengthen the internal management and construction, improve the comprehensive efficiency.

\section{References}

[1] Cai Shuping, the king Yang Yan university scientific research model, with the reform of the real management and optimization of. Industry and Technology Forum. No. 20. (2013)

[2] Liu Yingying, Chen Bingbing. The influence of scientific research in Universities on the local economy in Heilongjiang province. North China Economic and trade. No. 07. (2013)

[3] Qin Shaohua. The characteristics and management of scientific research in universities and Colleges. No.02. (2012)

[4] to speed up the docking of China's University research and enterprise needs. China industry. No. 03. (2012) 
[5] Shen Jun Weng. The change of scientific research development in Colleges and universities to create a new situation of scientific research work of. science and Technology Innovation Herald. No. 30. (2013) 